\title{
Brain Embolism Secondary to Cardiac Myxoma in Fifteen Chinese Patients
}

\author{
Youming Long ${ }^{1,2}$ and Cong Gao ${ }^{1,2}$ \\ ${ }^{1}$ Key Laboratory of Neurogenetics and Channelopathies of Guangdong Province and The Ministry of Education of China, \\ Institute of Neuroscience and the Second Affiliated Hospital of GuangZhou Medical University, 250 Changgang East Road, \\ Guangzhou, Guangdong 510260, China \\ ${ }^{2}$ Department of Neurology, The Second Affiliated Hospital of GuangZhou Medical University, 250 Changgang East Road, \\ Guangzhou, Guangdong 510260, China
}

Correspondence should be addressed to Cong Gao; smilegaocong@126.com

Received 27 October 2013; Accepted 5 January 2014; Published 9 March 2014

Academic Editors: L. P. Perrault and E. J. Thompson

Copyright (C) 2014 Y. Long and C. Gao. This is an open access article distributed under the Creative Commons Attribution License, which permits unrestricted use, distribution, and reproduction in any medium, provided the original work is properly cited.

Background. Heart myxoma-related embolisms commonly involve the central nervous system, but data are lacking in Chinese patients. Methods. 27 patients diagnosed with myxoma were reviewed retrospectively. Results. Among 27 patients, fourteen (51.9\%) patients were women. Fifteen (55.6\%) patients had brain embolisms. Rarely, patients were misdiagnosed with central nervous system vasculitis $(n=2)$, moyamoya disease $(n=1)$, and neuromyelitis optica $(n=1)$. We found positive associations between mRS $(>3)$ and female gender $(r=0.873, P<0.0001)$, infection $(r=0.722, P=0.002)$, severe complications $(r=0.722, P=0.002)$, systolic blood pressure (SBP) of $<120 \mathrm{mmHg}(r=0.6, P=0.018)$, WBC count of $>10 \times 10^{9} / \mathrm{L}(r=0.722, P=0.002)$, tumour size $(r=0.866, P<0.0001)$, bilateral brain lesions $(r=0.60, P=0.018)$, and total anterior circulation infarction (TACI) $(r=0.667$, $P=0.007)$. The independent relationships among these factors and outcomes could not be confirmed $(P>0.05)$. Conclusions. Neurologic manifestations in Chinese patients with cardiac myxoma-related stroke were complicated and multifarious. Female gender, infection, other severe complications, low SBP, tumour size, bilateral brain lesions, TACI, and high WBC counts could be associated with a poor prognosis.

\section{Introduction}

Cardiac primary neoplasms are rare with an incidence of $<0.2 \%$ at autopsy [1]. Among living patients who have undergone heart surgery, only $0.45 \%$ suffered from a heart tumour [2]. Myxomas, which are derived from multipotent mesenchymal cells of the endocardium [3], are the most common type of benign heart tumour, representing $50 \%$ to $83 \%$ of all primary cardiac tumours $[2,4,5]$. In recent years, increasingly more cases of cardiac myxoma [6] have been reported, including cases involving Chinese patients [5, 7].

The clinical manifestations of cardiac myxoma are generally nonspecific; a minority of patients are asymptomatic [6, 8]. The most common presentation is related to mitral valve obstruction and is characterised by palpitations, dizziness, dyspnoea, cough, heart failure, and syncope $[6,9]$. The second most common presentation involves embolism formation, which may occur in any extremity but commonly involves the CNS $[4,6,9,10]$.

Many unique manifestations or therapies for CNS embolism secondary to cardiac myxoma have been reported. However, large case studies of patients with cardiac myxomarelated CNS embolism have not been published, although a few previous series have been reported [11-15]. Neurologic manifestations of atrial myxomas have been reported in $12 \%$ to $45 \%$ of affected patients $[6,8,9,11,13,14]$ and were quite various. The neurologic signs and symptoms are usually a result of emboli from a myxomatous or tumour-adherent thrombus. Cerebral embolic events often occur before the onset of constitutional or obstructive symptoms at a rate of 
TABLE 1: Clinical features of patients with cardiac myxoma with brain embolism.

\begin{tabular}{|c|c|c|c|c|}
\hline Characteristic & $\begin{array}{c}\text { Total } \\
(n=27)\end{array}$ & $\begin{array}{c}\text { Embolism } \\
(n=15)\end{array}$ & $\begin{array}{c}\text { No embolism } \\
\quad(n=12)\end{array}$ & $P$ \\
\hline Female/male & $12 / 15$ & $9 / 6$ & $6 / 6$ & 0.863 \\
\hline Age, y $($ mean $\pm S D)$ & $57.3 \pm 13.5$ & $56.4 \pm 13.3$ & $58.4 \pm 14.1$ & 0.708 \\
\hline Hypertension, $n(\%)$ & $9(33.3 \%)$ & $6(40 \%)$ & $3(25 \% \%)$ & 0.683 \\
\hline Hyperlipidemia, $n(\%)$ & $5(18.5 \%)$ & $4(26.5 \%)$ & $1(8.3 \%)$ & 0.342 \\
\hline Vascular malformation, $n(\%)$ & $2(7.4 \%)$ & $2(13.3 \%)$ & 0 & 0.487 \\
\hline Diabetes at baseline, $n(\%)$ & $2(7.4 \%)$ & 0 & $2(16.7 \%)$ & 0.188 \\
\hline Coronary artery disease, $n(\%)$ & $3(11.1 \%)$ & $2(13.3 \%)$ & $1(8.3 \%)$ & 1 \\
\hline Atrial fibrillation, $n(\%)$ & $5(18.5 \%)$ & $3(20 \%)$ & $2(16.7 \%)$ & 1 \\
\hline Infection, $n(\%)$ & $8(29.6 \%)$ & $7(46.7 \%)$ & $1(8.3 \%)$ & 0.043 \\
\hline Death, $n(\%)$ & $4(14.8 \%)$ & $3(20 \%)$ & $1^{*}(8.3 \%)$ & 0.605 \\
\hline Complement $4, \mathrm{~g} / \mathrm{L}($ mean $\pm \mathrm{SD})$ & $0.32 \pm 0.08$ & $0.35 \pm 0.09$ & $0.27 \pm 0.06$ & 0.036 \\
\hline Low-density lipoprotein, mmol/L (mean \pm SD) & $2.72 \pm 0.84$ & $3.08 \pm 0.71$ & $2.23 \pm 0.78$ & 0.017 \\
\hline Creatinine kinase- $\mathrm{MB}, \mathrm{U} / \mathrm{L}($ mean $\pm \mathrm{SD})$ & $12.75 \pm 9.96$ & $16.64 \pm 11.66$ & $8.0 \pm 4.39$ & 0.05 \\
\hline Lactate dehydrogenase, $\mathrm{U} / \mathrm{L}($ mean $\pm \mathrm{SD})$ & $247.48 \pm 178.38$ & $316.42 \pm 208.51$ & $155.56 \pm 55.94$ & 0.037 \\
\hline Hydroxybutyrate dehydrogenase, U/L (mean $\pm \mathrm{SD}$ ) & $188.85 \pm 162.94$ & $246.45 \pm 202.77$ & $118.44 \pm 39.08$ & 0.078 \\
\hline Platelet count, $\times 10^{9} / \mathrm{L}($ mean $\pm \mathrm{SD})$ & $270.2 \pm 100.9$ & $286.2 \pm 119.6$ & $249.9 \pm 70.9$ & 0.383 \\
\hline Red blood cell count, $\times 10^{9} / \mathrm{L}($ mean $\pm \mathrm{SD})$ & $4.35 \pm 0.61$ & $4.55 \pm 0.51$ & $4.08 \pm 0.15$ & 0.054 \\
\hline White blood cell count, $\times 10^{9} / \mathrm{L}($ mean \pm SD) & $10.3 \pm 3.9$ & $11.6 \pm 4.4$ & $8.6 \pm 2.3$ & 0.049 \\
\hline \multicolumn{5}{|l|}{ Echocardiography Features } \\
\hline Myxomas length $\mathrm{cm}($ mean $\pm \mathrm{SD})$ & $4.31 \pm 1.68$ & $4.04 \pm 1.21$ & $4.65 \pm 2.14$ & 0.233 \\
\hline Attached to atrial septum, $n(\%)$ & $24(88.9 \%)$ & $14(93.3 \%)$ & $10(83.3 \%)$ & 0.569 \\
\hline High echo, $n(\%)$ & $22(81.5 \%)$ & $12(80 \%)$ & $10(83.3 \%)$ & 1 \\
\hline Irregular shape, $n(\%)$ & $23(85.2 \%)$ & $15(100 \%)$ & $8(66.7 \%)$ & 0.028 \\
\hline Peduncle, $n(\%)$ & $21(77.8 \%)$ & $11(73.3 \%)$ & $10(83.3 \%)$ & 0.662 \\
\hline Prolapse into valve, $n$ (\%) & $22(81.5 \%)$ & $14(93.3 \%)$ & $8(66.7 \%)$ & 0.139 \\
\hline Aortosclerosis, $n(\%)$ & $17(63.0 \%)$ & $10(66.7 \%)$ & $7(58.3 \%)$ & 0.371 \\
\hline Aortic valve regurgitation, $n(\%)$ & $10(37.0 \%)$ & $5(33.3 \%)$ & $5(41.7 \%)$ & 0.706 \\
\hline Mitral valve regurgitation, $n(\%)$ & $12(44.4 \%)$ & $7(46.7 \%)$ & $5(41.7 \%)$ & 1 \\
\hline Tricuspid valve regurgitation, $n(\%)$ & $15(55.6 \%)$ & $7(46.7 \%)$ & $8(66.7 \%)$ & 0.441 \\
\hline Lower left ventricular compliance, $n(\%)$ & $10(37.0 \%)$ & $7(46.7 \%)$ & $3(25 \%)$ & 0.424 \\
\hline Heart enlargement, $n(\%)$ & $13(48.1 \%)$ & $6(40 \%)$ & $7(58.3 \%)$ & 0.449 \\
\hline
\end{tabular}

${ }^{*}$ One patient with right atrium myxoma and patent foramen ovale died of the complication of surgery.

up to $80 \%$ [12]. Other seldom seen neurological presentations occur in some patients, including intracerebral haemorrhage $[14,16]$, brain metastasis [17], and intracranial aneurysm [14].

Although atrial myxoma is associated with a high incidence of stroke, few patients die of cerebral embolism complications $[17,18]$. No consistent, definitive prognosis has been established in these severely affected patients after stroke [19].

There are no published series that describe CNS manifestations and outcomes of cardiac primary tumours in Chinese patients with embolism. In the present study, we collected cases of Chinese patients affected by cardiac myxoma-related brain embolism and focused on the particular clinical characteristics of the embolisms.

\section{Patients and Methods}

27 patients with definite cardiac myxomas were evaluated by medical record reviews and interviews in the present study.

Data were retrospectively collected from patient records. At baseline, demographic data (age and sex) and history of conventional vascular risk factors were obtained. All patients with stroke underwent neurologic testing (brain CT or MRI, magnetic resonance angiography, or cerebral angiography) or neurologic consultation routinely within 24 to 48 hours after the attack. Laboratory investigations for vascular risk factors, duplex sonography of the carotid and vertebral arteries, and a thorough cardiac investigation were performed.

Cerebral infarctions were classified according to the OCSP systems [20]. The National Institute of Health stroke scale was used during the acute phase, and the modified Rankin Scale (mRS) was available and used in 15 patients with brain embolisms. The mRS score 3 months after onset was classified as independent (score of 0-2) or dependent/dead (score of 3-6).

Permission for the study was obtained from the Local Ethics Committees of the Second Affiliated Hospital of Guangzhou Medical University.

2.1. Statistical Analyses. Statistical analyses were performed with Fisher's exact test for binary and categorical data and the Mann-Whitney $U$ test for continuous variables. Correlations 
TABLE 2: Features of different outcomes of patients with myxoma with brain embolism.

\begin{tabular}{|c|c|c|c|}
\hline Characteristic & MRS $0-2(n=6)$ & MRS 3-6 $(n=9)$ & $P$ \\
\hline Female/male & $0 / 6$ & $8 / 1$ & 0.001 \\
\hline Age, y $($ mean $\pm S D)$ & $55.44 \pm 14.20$ & $57.83 \pm 10.54$ & 0.748 \\
\hline Infection, $n(\%)$ & $1(16.7 \%)$ & $8(88.9 \%)$ & 0.011 \\
\hline Other severe complications ${ }^{*}, n(\%)$ & $1(16.7 \%)$ & $8(88.9 \%)$ & 0.011 \\
\hline Hemorrhagic transformation, $n(\%)$ & $1(16.7 \%)$ & $5(55.6 \%)$ & 0.287 \\
\hline Accompanying disease, $n(\%)$ & $3(50 \%)$ & $7(77.8 \%)$ & 0.329 \\
\hline Systolic blood pressure, $\mathrm{mm} \mathrm{Hg}($ mean $\pm \mathrm{SD})$ & $135 \pm 9.61$ & $116.89 \pm 13.71$ & 0.032 \\
\hline Diastolic blood pressure, $\mathrm{mm} \mathrm{Hg}($ mean $\pm \mathrm{SD})$ & $86.2 \pm 11.07$ & $71.89 \pm 12.53$ & 0.058 \\
\hline Conscious disturbance, $n(\%)$ & 0 & $6(66.7 \%)$ & 0.028 \\
\hline \multicolumn{4}{|l|}{ MRI } \\
\hline Bilateral lesions, $n(\%)$ & $1(16.7 \%)$ & $7(77.8 \%)$ & 0.041 \\
\hline Lesions count $($ mean \pm SD) & $2.17 \pm 1.21$ & $4 \pm 1.33$ & 0.026 \\
\hline Total anterior circulation, $n(\%)$ & 0 & $6(66.7 \%)$ & 0.028 \\
\hline Posterior circulation, $n(\%)$ & $1(16.7 \%)$ & $5(55.6 \%)$ & 0.287 \\
\hline $\mathrm{WBC}, \times 10^{9} / \mathrm{L}($ mean $\pm \mathrm{SD})$ & $8.21 \pm 3.18$ & $13.52 \pm 3.52$ & 0.029 \\
\hline Hemoglobin, g/L & $139.4 \pm 20.27$ & $117.4 \pm 14.89$ & 0.053 \\
\hline $\mathrm{MCH}$ pq $($ mean $\pm \mathrm{SD})$ & $29.96 \pm 2.31$ & $26.29 \pm 3.21$ & 0.059 \\
\hline $\mathrm{MCHC}, \mathrm{g} / \mathrm{L}($ mean $\pm \mathrm{SD})$ & $339.2 \pm 6.62$ & $320.3 \pm 13.35$ & 0.022 \\
\hline $\operatorname{IgM}($ mean $\pm \mathrm{SD})$ & $0.61 \pm 0.18$ & $1.22 \pm 0.38$ & 0.023 \\
\hline \multicolumn{4}{|l|}{ Echocardiography } \\
\hline $\mathrm{ROVT}, \mathrm{cm}($ mean $\pm \mathrm{SD})$ & $2.97 \pm 0.23$ & $2.60 \pm 0.25$ & 0.010 \\
\hline $\mathrm{AO}, \mathrm{cm}($ mean $\pm \mathrm{SD})$ & $3.24 \pm 0.03$ & $2.78 \pm 0.22$ & 0.026 \\
\hline Myxomas length $\mathrm{cm}($ mean $\pm \mathrm{SD})$ & $2.89 \pm 1.39$ & $4.6 \pm 0.87$ & 0.009 \\
\hline Myxomas (length + width $) \mathrm{cm}($ mean $\pm \mathrm{SD})$ & $4.93 \pm 2.27$ & $8.0 \pm 2.18$ & 0.017 \\
\hline
\end{tabular}

between multiple variables and functional outcomes were analysed by Spearman's correlation test. Predictors of prognosis were analysed by binary logistic regression analysis, which allows for adjustment for confounding factors. Analyses were undertaken with the SPSS (version 11.1) software package.

\section{Results}

3.1. Demographic and Clinical Characteristics. Among the 27 patients with cardiac myxoma, the mean age was $57.3 \pm$ 13.5 years (range, 34-85 years), and 14 (51.9\%) patients were female. The left atrium (LA) was the most commonly observed location of cardiac myxomas (24 patients $(88.9 \%)$ ), followed by the right atrium $(2(7.4 \%))$ and the LA and ventricles $(1(3.7 \%))$.

The most common initial manifestation of myxoma in our series was brain embolism (15 patients (55.6\%)), and the second was related to mitral valve obstruction: palpitations (7 patients $(25.9 \%))$ and Aase syndrome (1 patient $(3.7 \%)$ ). Three patients $(11.1 \%)$ had no signs before surgery. Among the 25 patients with LA myxomas, 15 (60\%) developed an embolism at the first attack.

3.2. Comparison of Patients with Cardiac Myxoma with and without Brain Embolism. The characteristics of these two groups of patients are shown in Table 1. No statistically significant differences in sex, age, and comorbidities were identified between the groups $(P>0.05)$. Patients with brain embolism were more likely to have infection on admission $(P=0.043)$. Table 1 also shows a statistically significantly higher white blood cell (WBC) count, complement 4 level, low-density lipoprotein level, and lactate dehydrogenase level in the patients with brain embolism on admission. Transthoracic echocardiography (TTE) results were available in all 27 patients. Fifteen (100\%) patients with embolism had an irregular morphology compared with the patients without embolism (66.7\%). However, other manifestations of TTE were not significantly different between the two groups. Logistic regression analysis showed that none of the factors showing significant differences (infection, complement 4 level, low-density lipoprotein level, creatine kinase $\mathrm{MB}$ level, lactate dehydrogenase level, WBC count, and irregular morphology) had predictive value for embolism formation $(P>0.05)$.

3.3. Clinical Features of Patients with Cardiac Myxoma with Brain Embolism. Ten (66.7\%) patients had comorbidities (hypertension, hyperlipidemia, vascular malformation, hyperthyroidism, coronary heart disease, or atrial fibrillation). Motor deficits were seen in all patients with embolism at onset. Symptoms of conscious disturbance were the initial manifestation in 6 of 15 (40\%) patients with embolism. Five of $15(33.3 \%)$ patients had aphasia, and $3(20 \%)$ had vertigo. Two (13.3\%) patients had seizure attacks, and one had right vision loss because of central retinal artery occlusion. One patient had neuromyelitis optica-like manifestations at the onset of attack (Figure 1). One patient experienced two attacks and 


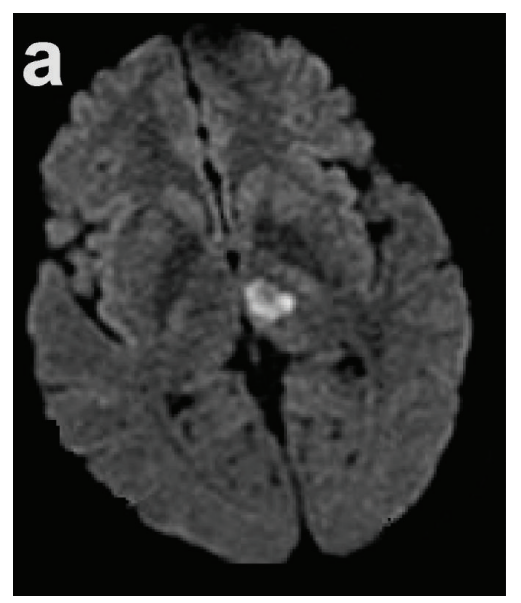

(a)



(b)

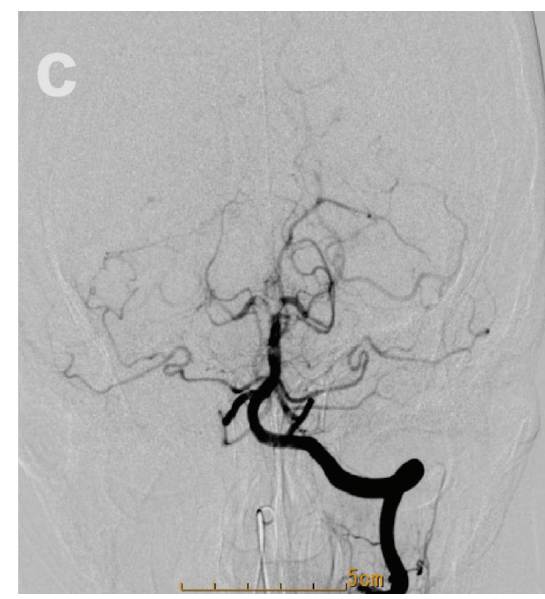

(c)

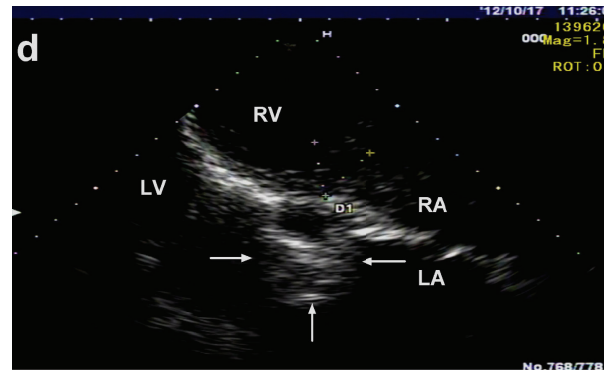

(d)

FiguRE 1: A patient presented with NMO-like attack. A 34-year-old woman with bilateral impaired vision, double vision, quadriplegia, dysuria, and internuclear ophthalmoplegia had normal brain CT results on 14 October 2012. Brain MRI showed multiple new lesions in brain. (a) MRI revealed abnormalities beside the third ventricle. (b) MRI revealed lesions in the pons. (c) DSA revealed occlusion of the top of the basilar artery. (d) Echocardiography showed a highly mobile mass attached to the fossa ovalis of the left atrium (arrow).

was diagnosed with CNS vasculitis and moyamoya disease (Figure 2). Embolism-related complications occurred in 10 of the $15(66.7 \%)$ patients. Infection was the most common complication (8 patients $(53.3 \%)$ ). One patient died of sudden death. Two patients died of hernias after the embolism. Thus, the fatality rate was $20 \%$ (3 of 15) among patients with embolism. Only one patient had no symptoms 24 months after tumour resection.

Neuroimaging was performed on all patients with embolism. Twelve of 15 (80\%) patients had multiple cerebral infarcts; in $8(53.3 \%)$, the infarctions involved the bilateral brain. Six (40\%) patients had total anterior circulation infarction (TACI), and eight (53.3\%) had partial anterior circulation infarction. Six (40\%) patients had posterior circulation infarction, and five $(33.3 \%)$ had anterior circulation infarction. The temporal lobe $(n=9)$, parietal lobe $(n=8)$, frontal lobe $(n=7)$, basal ganglia $(n=7)$, and cerebellum $(n=7)$ were the most commonly involved regions. No patients had spinal cord infarctions. Brain haemorrhage was seen in six $(40 \%)$ patients. Not only did the location of the infarction differ but also its form differed among the 15 patients. Sporadic infarction occurred all in male patients, and multiple large lesions were found in most female patients (7 of $9(77.8 \%))$. Three $(20 \%)$ patients had cortical laminar necrosis (CLN), an unusual MRI finding (Figure 3) [21].
3.4. Clinical Outcomes. At 3 months after onset, the mean mRS score of the patients with myxoma-related stroke was $3.34 \pm 2.16$ (range, 0-6). Six (40\%) patients had a good outcome (mRS score of $0-2)$, and nine $(60 \%)$ had a severe outcome (mRS score of 3-6). During the follow-up period (3-108 months), none of the 12 surviving patients experienced tumour recurrence or myxoma-related embolism.

Patients with severe outcomes (mRS score of 3-6) were almost all women $(P=0.001)$. They more often had infection $(P=0.011)$ and other severe complications $(P=0.011)$.

When Spearman correlation coefficients were calculated for prognosis and other variables, we found highly positive associations between high mRS scores $(>3)$ and female gender $(r=0.873, P<0.0001)$, infection $(r=0.722$, $P=0.002)$, severe complications $(r=0.722, P=0.002)$, systolic blood pressure (SBP) of $<120 \mathrm{mmHg}(r=0.6, P=$ $0.018)$, WBC count of $>10 \times 10^{9} / \mathrm{L}(r=0.722, P=0.002)$, tumour length + width of $>5 \mathrm{~cm}(r=0.866, P<0.0001)$, bilateral brain lesions $(r=0.60, P=0.018)$, and TACI ( $r=0.667, P=0.007)$. However, on stepwise multiple logistic regression analysis, the independent relationships among these factors (infection, severe complications, WBC count, TACI, and admission SBP) and severe outcomes could not be confirmed (Table 2). 


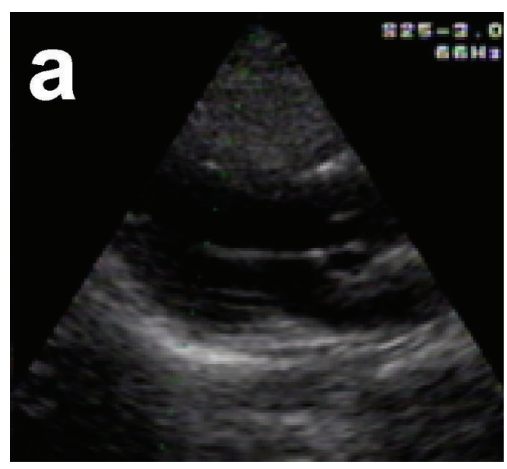

(a)

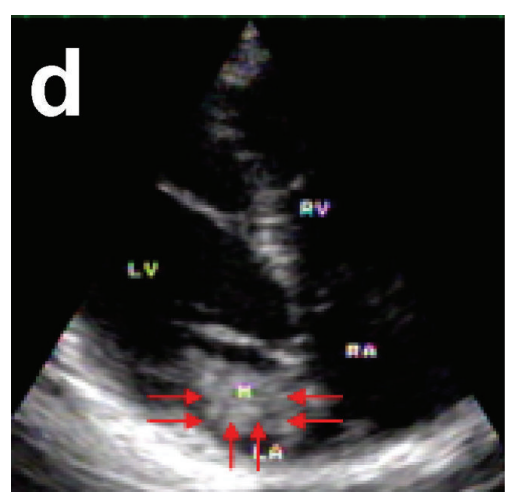

(d)

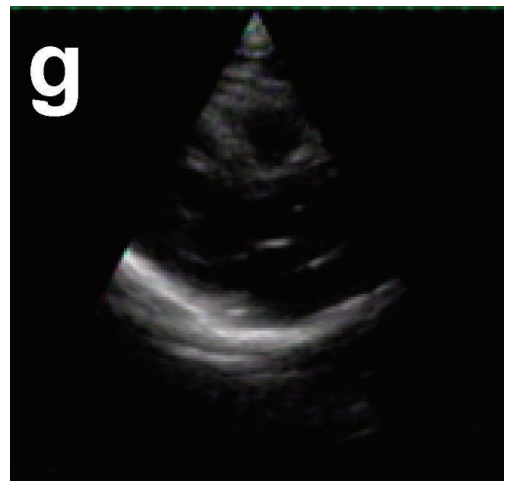

(g)

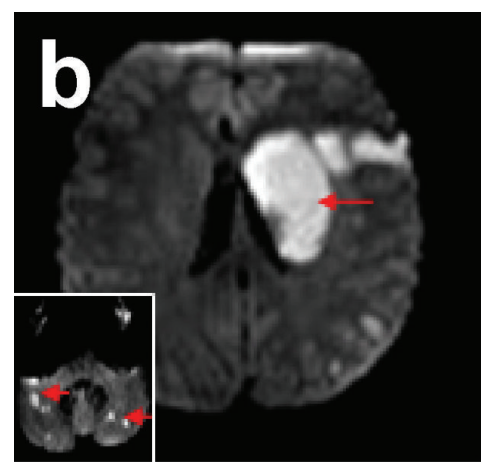

(b)

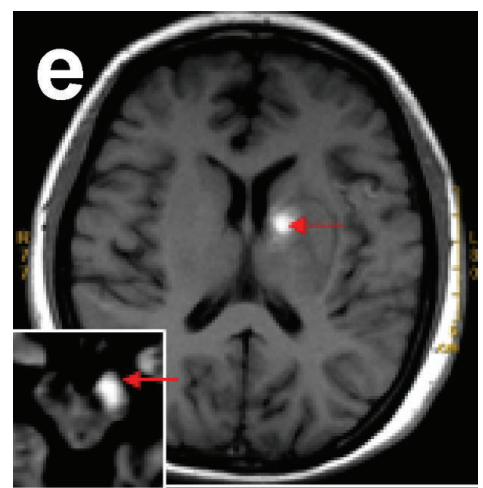

(e)

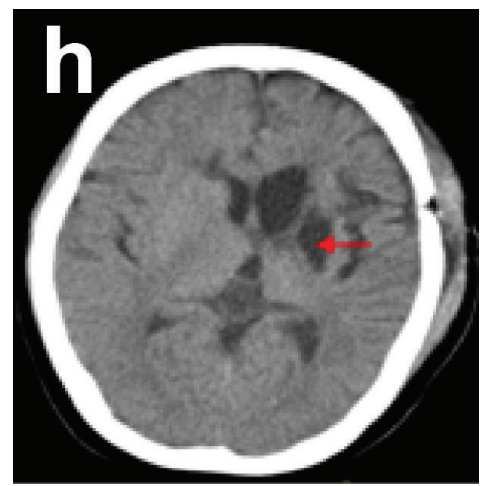

(h)

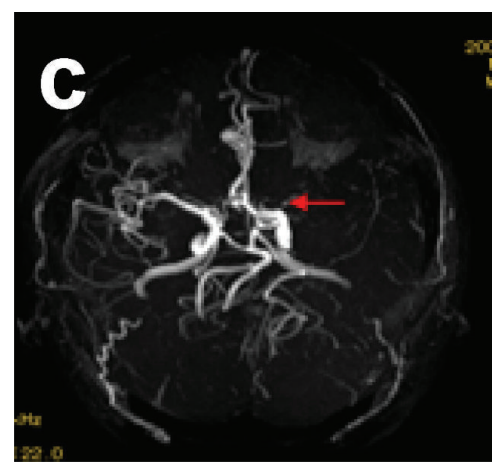

(c)

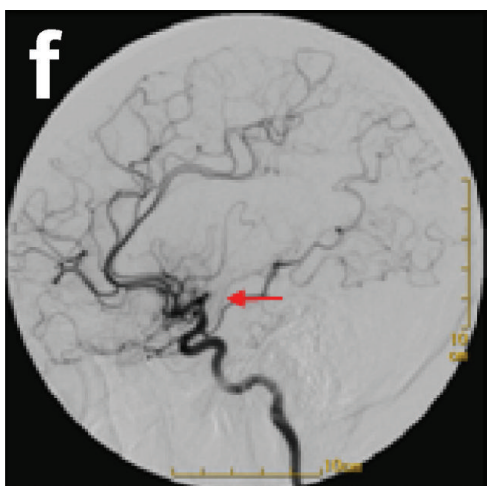

(f)

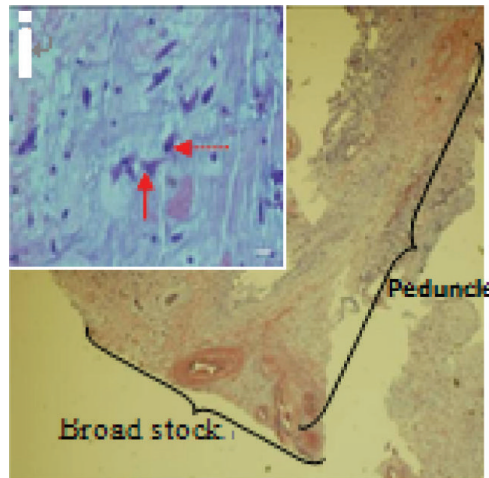

(i)

FIGURE 2: Patient presented with moyamoya disease. (a) Echocardiography with normal findings at the time of the first attack. (b) Brain MRI showed multiple new lesions in the left brain and bilateral cerebellum (arrow) at the first attack. (c) MRA revealed occlusion of the middle cerebral artery (arrow). (d) Echocardiography revealed a highly mobile mass attached to the fossa ovalis (arrow) at the second attack. (e) The second MRI showed a haematoma (dotted arrow) in the left basal ganglia and new infarction lesions in the left cerebral peduncle. (f) DSA showed occlusion of the middle cerebral artery (arrow) and secondary formation of an unusual vascular network (not shown). (g) After surgery, echocardiography showed that the mass in the left atrium had disappeared. (h) CT showed a stroke capsule in the left brain (arrow). (i) Histopathology showed spindle (dotted arrow) and stellate mesenchymal cells (arrow) that were embedded in the myxomatous stroma.

\section{Discussion}

Our female/male ratio (14/13) in cardio myxomas differs from that of most other studies, in which this ratio varies from 1.7 to $4.4: 1[6,22]$, including a large sample from China [7]. Only one Chinese study showed results consistent with ours; in that study, 39 of 75 patients with cardiac myxomas were women [5]. Whether this female predominance is correlated with the pathogenesis of cardiac myxoma is unclear. One previous report indicated that gender is associated with neurologic or embolic symptoms in men and systemic symptoms in women [6]. In our series, we did not find that female gender was associated with embolism when comparing the embolic and nonembolic groups, which is similar to the results of a series in Korea [13]. In terms of gender, the present results could be of major interest for patients with brain embolism. 


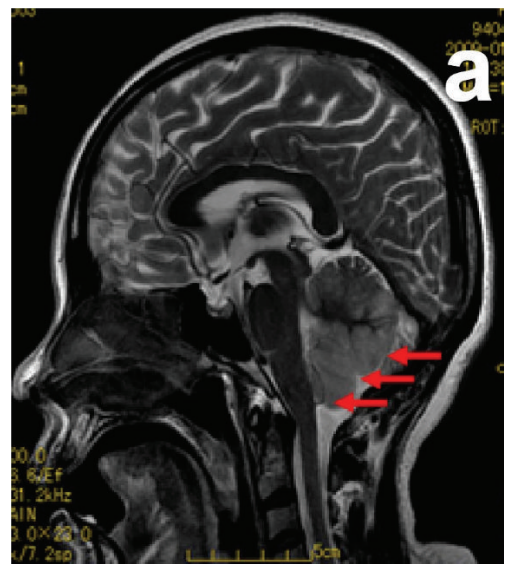

(a)

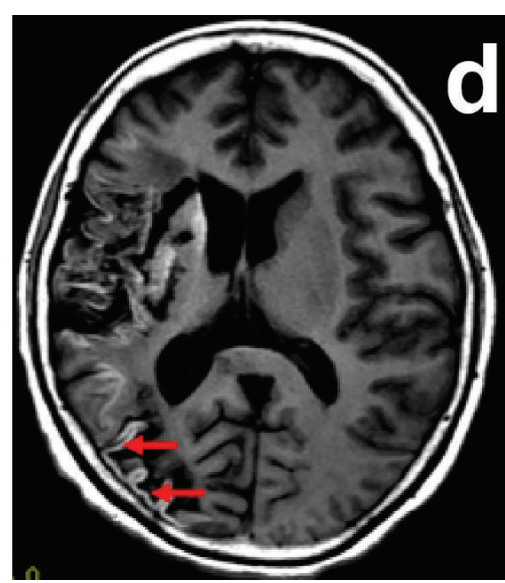

(d)

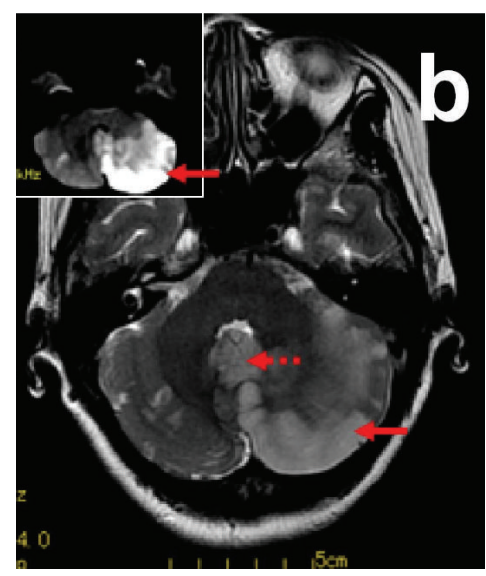

(b)

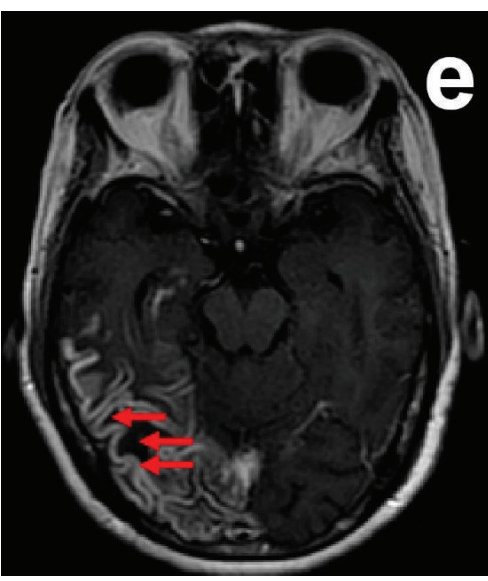

(e)

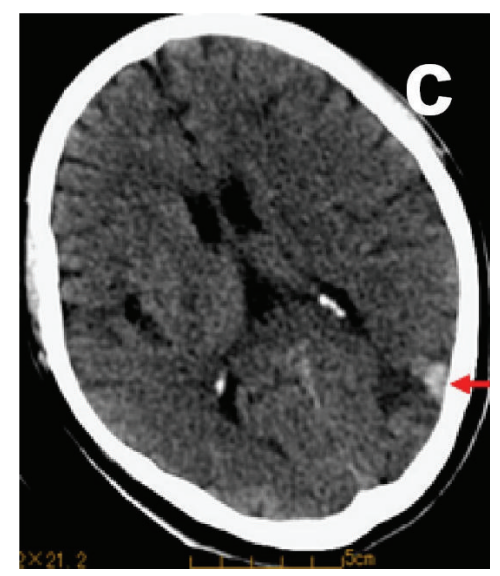

(c)



(f)

FIgURE 3: Unusual imaging findings in patients with myxoma with embolism. (a) A patient's death was due to the mass effect of a large infarction associated with compression. (b) Cross section of MRI revealed a new infarction of his left cerebellum (arrow). Part of the infarction compressed the fourth ventricle (dotted arrow). (c) CT showed a haematoma of the left cornu posterius ventriculi in the same patient (arrow). ((d)-(f)) MRI revealed a linear hyperintense band along the gyral margins (arrow) on T1-weighted imaging, which was defined as cortical laminar necrosis.

Indeed, there was an obvious female predominance in worse outcomes (mRS score of $>3$ ). Although it cannot be considered an independent predictor of poor outcome in this small sample, it had a high correlation with poor prognosis $(r=0.873 ; P<0.0001)$. In our opinion, female patients with myxomas should be offered close monitoring and early surgery because of the possibility of a worse outcome, including death.

The data in our study could be of major interest in terms of disease manifestation in the 15 patients with embolism. First, most myxoma-related emboli occluded large arteries or multiple vascular territories; eight $(53.3 \%)$ patients had multiple infarctions in the bilateral brain, and six (40\%) had total anterior circulation infarction. Our occurrence rate of multiple infarctions in the bilateral brain was higher than that in previous studies (3 of 11 in Korea [13] and 0 of 9 in the United States [14]). This indicates that our patients with cardiac myxoma with embolism had more severe injuries. Second, patients had special manifestations that had not been reported in previous studies. Neuromyelitis optica (NMO) may sometimes appear similar to top-of-thebasilar syndrome [23]. But in the present study, a patient, who had pathologically confirmed myxoma-related embolism, presented with NMO-like manifestation (Figure 1). And there were other two patients who had a prior presumptive diagnosis of CNS vasculitis before a definitive diagnosis was reached, especially a woman also with moyamoya disease, which has never been reported (Figure 2). Third, unusual MRI findings in patients with myxoma-related embolism are another interesting factor [14]. In our study, $20 \%$ of patients had CLN. CLN represents neuronal ischemia accompanied by gliosis and layered deposition of fat-laden macrophages [24].

Complications after ischemic stroke are common, and they may adversely impact the clinical outcome. Although comprising a small sample, our patients had a high complication rate of $73.3 \%$ (11 of 15 patients). Herniation $(n=2)$, haemorrhagic transformation $(n=6)$, and epilepsy $(n=2)$ were the cerebral complications found in seven patients, six $(85.7 \%)$ of whom had a poor outcome. In a previous study, 
poor outcomes and death were more frequent in patients with cerebral embolism of cardiac origin [25, 26], similar to our present results. In the present study, two patients died of transtentorial herniation and cerebellar tonsillar herniation, respectively. Herniation and death seldom occurred in patients with myxoma in several previous series [11-14], but death was reported in a single case report [27]. The most severe cardiac complication of myxomas is sudden death. Sudden death secondary to primary cardiac tumours is very infrequent and limited to single case reports in the literature. A review indicated that there were 120 cases (approximately $0.0025 \%$ ) of sudden death attributed to primary cardiac tumours from 1982 to 1991 [28]. In the present study, one was a case of sudden death, the rarest complication of heart tumour. She was suddenly unresponsive, and her presenting rhythm was asystole. To our knowledge, this is the first report of a patient with sudden death secondary to LA tumour after brain embolism. This case indicates the importance of early surgery to decrease such unusual death.

Infection was the most common complication among our patients with cardiac myxoma with brain embolism ( 9 of 15 patients (75\%)). Previous studies on acute stroke have demonstrated that pneumonia and urinary tract infection are independently associated with poor outcomes or increase the risk of death $[29,30]$. Although stepwise multiple logistic regression analysis did not show infection as an independent predictor of poor outcomes in our small sample, it was highly related to poor prognosis ( $r=0.722 ; P=0.002)$. Therefore, given the higher infection and mortality rates in our patients compared with other causes of stroke, prophylactic antibiotic treatment is necessary in patients with severe embolism secondary to heart myxoma.

There are certain limitations to our study. Because of the retrospective nature of the study, uncontrolled or unknown factors that could affect the outcome might have confounded our results. It is also possible that retrospective identification of patients might have caused selection bias. The sample of 15 patients from a single centre in our hospital was still small. However, to the best of our knowledge, the present study represents the largest clinical series of brain embolism related to cardiac myxoma, and it is helpful for the clinician.

In summary, most patients with myxoma-related embolism had complications and poor outcomes. Female gender, infection, complications, low SBP, tumour size, bilateral brain lesions, TACI, and WBC counts could be associated with the outcome. We hope that a large-sample, multicentre, prospective evaluation will be performed in our Chinese patients with myxoma-related embolism.

\section{Conflict of Interests}

The authors declare that there is no conflict of interests regarding the publication of this paper.

\section{Acknowledgments}

This study was supported by the Plan of China Postdoctoral Science Foundation Grant (2012M521586) and Pearl Rivers Science and Technology Star Grant (2012J2200029).

\section{References}

[1] K. Reynen, "Frequency of primary tumors of the heart," American Journal of Cardiology, vol. 77, no. 1, p. 107, 1996.

[2] C. M. Steger, T. Hager, and E. Ruttmann, "Primary cardiac tumours: a single-center 41-year experience," ISRN Cardiology, vol. 2012, Article ID 906109, 7 pages, 2012.

[3] L. Johansson, "Histogenesis of cardiac myxomas. An immunohistochemical study of 19 cases, including one with glandular structures, and review of the literature," Archives of Pathology and Laboratory Medicine, vol. 113, no. 7, pp. 735-741, 1989.

[4] P. Blondeau, "Primary cardiac tumors-French studies of 533 cases," Thoracic and Cardiovascular Surgeon, Supplement, vol. 38, no. 2, pp. 192-195, 1990.

[5] Q. Meng, H. Lai, J. Lima, W. Tong, Y. Qian, and S. Lai, "Echocardiographic and pathologic characteristics of primary cardiac tumors: a study of 149 cases," International Journal of Cardiology, vol. 84, no. 1, pp. 69-75, 2002.

[6] L. Pinede, P. Duhaut, and R. Loire, "Clinical presentation of left atrial cardiac myxoma: a series of 112 consecutive cases," Medicine, vol. 80, no. 3, pp. 159-172, 2001.

[7] S. Liu, Z. Wang, A. Q. Chen, G. H. Zhou, Z. B. Jiang, and M. D. Xiao, "Cardiac myxoma and myxosarcoma: clinical experience and immunohistochemistry," Asian Cardiovascular and Thoracic Annals, vol. 10, no. 1, pp. 8-11, 2002.

[8] K. Reynen, "Medical progress: cardiac myxomas," The New England Journal of Medicine, vol. 333, no. 24, pp. 1610-1617, 1995.

[9] M. L. Markel, B. F. Waller, and W. F. Armstrong, "Cardiac myxoma. A review," Medicine, vol. 66, no. 2, pp. 114-125, 1987.

[10] Q. Li, H. Shang, D. Zhou, R. Liu, L. He, and H. Zheng, "Repeated embolism and multiple aneurysms: central nervous system manifestations of cardiac myxoma," European Journal of Neurology, vol. 15, no. 12, pp. el12-el13, 2008.

[11] B. A. Sandok, I. Von Estorff, and E. R. Giuliani, "CNS embolism due to atrial myxoma. Clinical features and diagnosis," Archives of Neurology, vol. 37, no. 8, pp. 485-488, 1980.

[12] L. E. Knepper, J. Biller, H. P. Adams Jr., and A. Bruno, "Neurologic manifestions of atrial myxoma. A 12-year experience and review," Stroke, vol. 19, no. 11, pp. 1435-1440, 1988.

[13] S.-J. Lee, J.-H. Kim, C.-Y. Na, and S.-S. Oh, "Eleven years' experience with Korean cardiac myxoma patients: focus on embolic complications," Cerebrovascular Diseases, vol. 33, no. 5, pp. 471-479, 2012.

[14] V. H. Lee, H. M. Connolly, and R. D. Brown Jr., "Central nervous system manifestations of cardiac myxoma," Archives of Neurology, vol. 64, no. 8, pp. 1115-1120, 2007.

[15] A. W. Elbardissi, J. A. Dearani, R. C. Daly et al., "Embolic potential of cardiac tumors and outcome after resection: a casecontrol study," Stroke, vol. 40, no. 1, pp. 156-162, 2009.

[16] V. M. Macaulay, P. J. Crawford, and R. O. McKeran, "Atrial myxoma presenting with cerebral haemorrhage," Postgraduate Medical Journal, vol. 61, no. 714, pp. 331-332, 1985.

[17] H. K. Ng and W. S. Poon, "Cardiac myxoma metastasizing to the brain. Case report," Journal of Neurosurgery, vol. 72, no. 2, pp. 295-298, 1990.

[18] W. T. Browne, E. F. M. Wijdicks, J. E. Parisi, and R. W. Viggiano, "Fulminant brain necrosis from atrial myxoma showers," Stroke, vol. 24, no. 7, pp. 1090-1092, 1993.

[19] D. P. Roeltgen, G. R. Weimer, and L. P. Patterson, "Delayed neurologic complications of left atrial myxoma," Neurology, vol. 31, no. 1, pp. 8-13, 1981. 
[20] P. Sandercock, A. Molyneux, and C. Warlow, "Value of computed tomography in patients with stroke: oxfordshire community stroke project," British Medical Journal, vol. 290, no. 6463, pp. 193-197, 1985.

[21] C. Kesavadas, K. Santhosh, B. Thomas et al., "Signal changes in cortical laminar necrosis-evidence from susceptibilityweighted magnetic resonance imaging," Neuroradiology, vol. 51, no. 5, pp. 293-298, 2009.

[22] N. P. Patil, N. Dutta, S. Satyarthy, M. A. Geelani, D. Kumar Satsangi, and A. Banerjee, "Cardiac myxomas: experience over one decade," Journal of Cardiac Surgery, vol. 26, no. 4, pp. 355359, 2011.

[23] M. Niino, H. Uesugi, T. Takahashi et al., "Recurrent brainstem lesions mimicking infarctions in an elderly patient with neuromyelitis optica spectrum disorder," Internal Medicine, vol. 51, no. 7, pp. 809-812, 2012.

[24] N. Siskas, A. Lefkopoulos, I. Ioannidis, A. Charitandi, and A. S. Dimitriadis, "Cortical laminar necrosis in brain infarcts: serial MRI,” Neuroradiology, vol. 45, no. 5, pp. 283-288, 2003.

[25] A. I. Qureshi, J. I. Suarez, A. M. Yahia et al., "Timing of neurologic deterioration in massive middle cerebral artery infarction: a multicenter review," Critical Care Medicine, vol. 31, no. 1, pp. 272-277, 2003.

[26] J. Biller, H. P. Adams Jr., A. Bruno, B. B. Love, and E. E. Marsh III, "Mortality in acute cerebral infarction in young adults-a ten-year experience," Angiology, vol. 42, no. 3, pp. 224-230, 1991.

[27] H. P. Bienfait and L. C. M. Moll, "Fatal cerebral embolism in a young patient with an occult left atrial myxoma," Clinical Neurology and Neurosurgery, vol. 103, no. 1, pp. 37-38, 2001.

[28] S. J. Cina, J. E. Smialek, A. P. Burke, R. Virmani, and G. M. Hutchins, "Primary cardiac tumors causing sudden death: a review of the literature," American Journal of Forensic Medicine and Pathology, vol. 17, no. 4, pp. 271-281, 1996.

[29] H.-C. Koennecke, W. Belz, D. Berfelde et al., "Factors influencing in-hospital mortality and morbidity in patients treated on a stroke unit," Neurology, vol. 77, no. 10, pp. 965-972, 2011.

[30] K.-S. Hong, D.-W. Kang, J.-S. Koo et al., "Impact of neurological and medical complications on 3-month outcomes in acute ischaemic stroke," European Journal of Neurology, vol. 15, no. 12, pp. 1324-1331, 2008. 


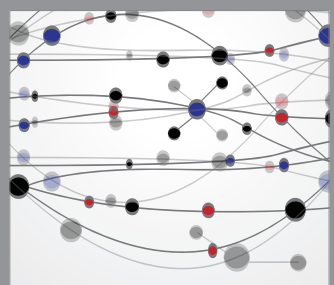

The Scientific World Journal
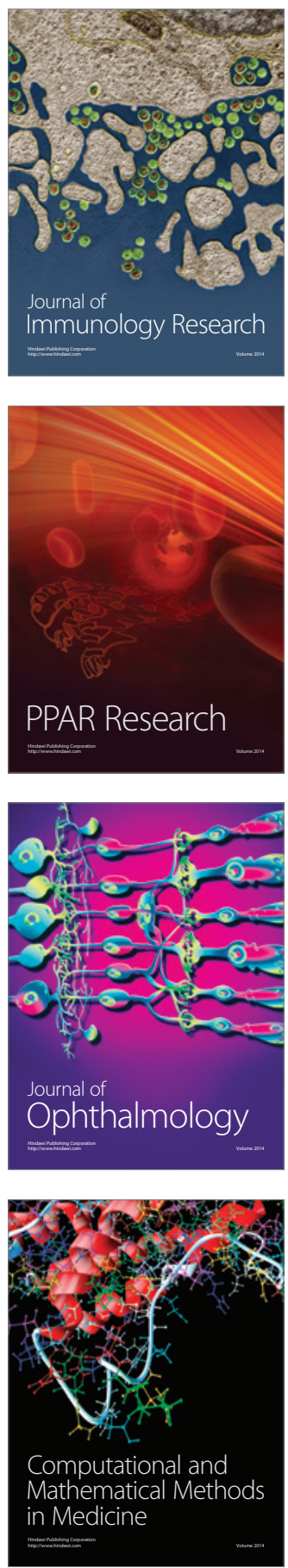

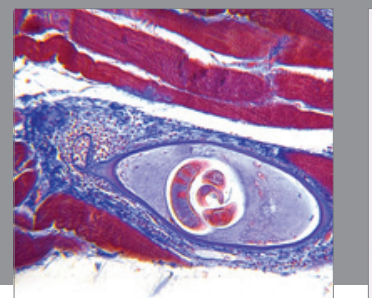

Gastroenterology

Research and Practice
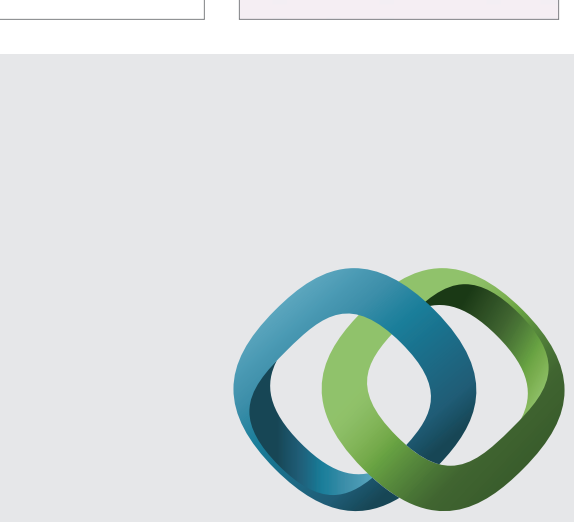

\section{Hindawi}

Submit your manuscripts at

http://www.hindawi.com
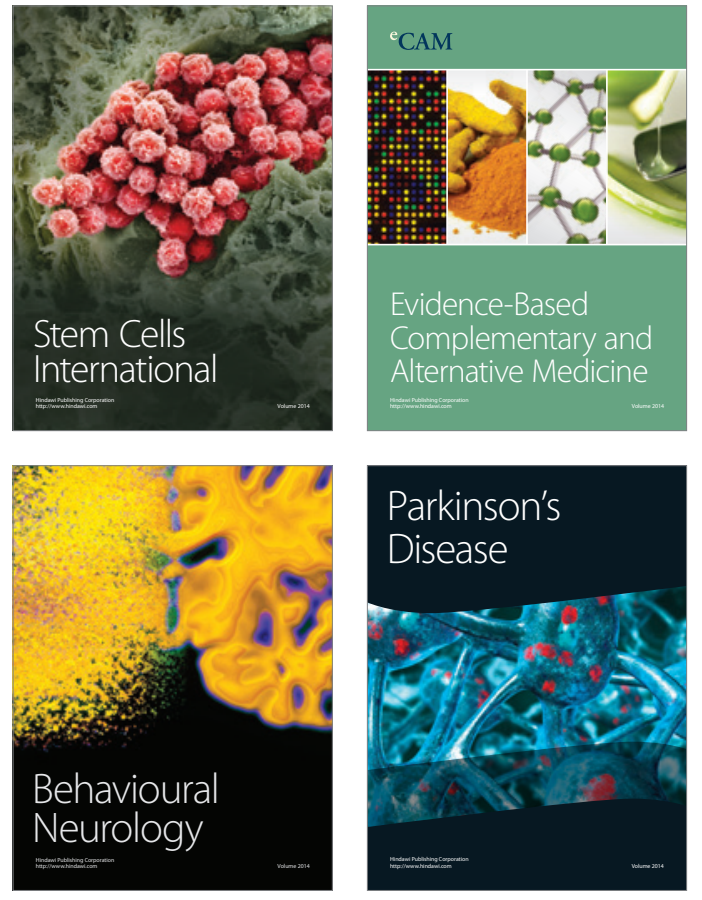
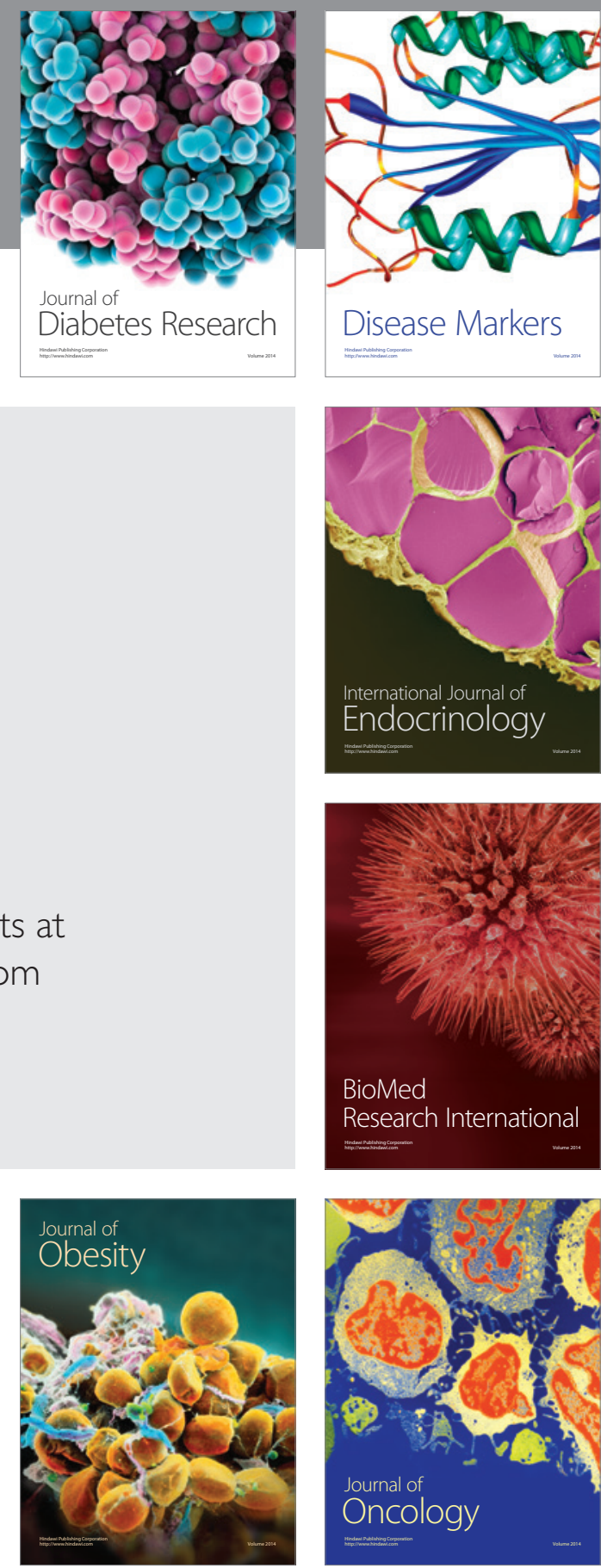

Disease Markers
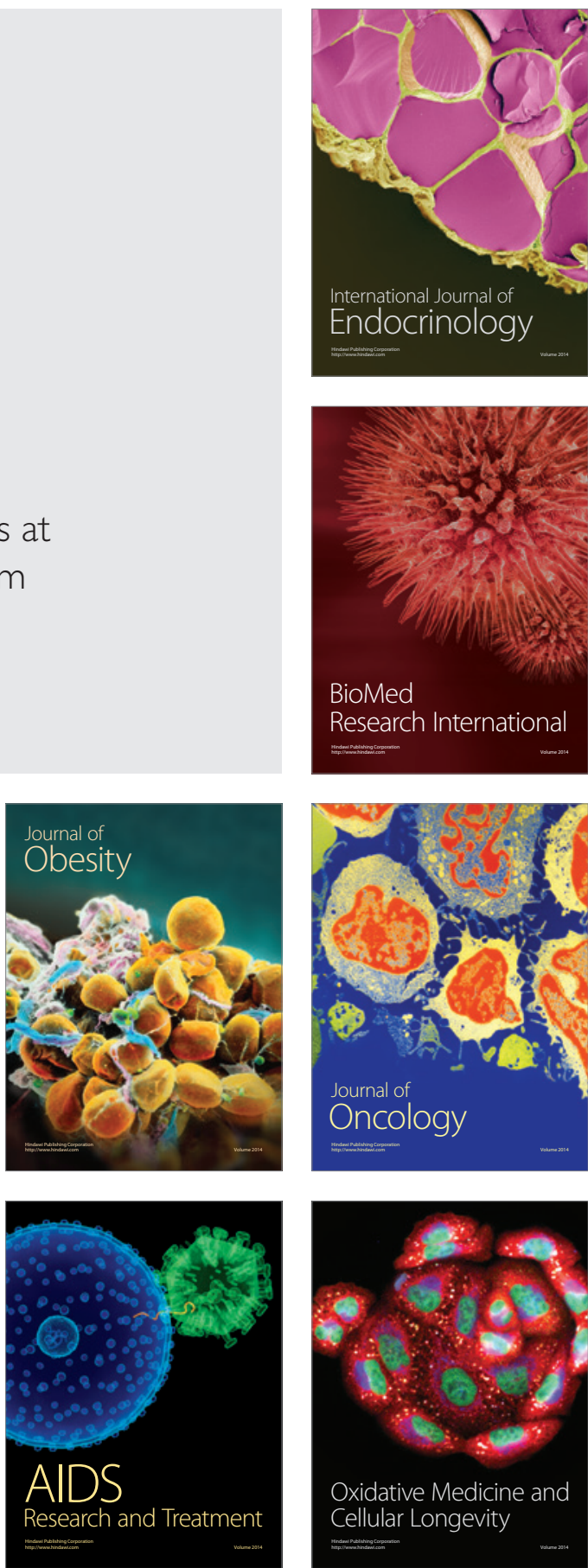